\title{
Experimental Study on the Mechanism of Hot Zone Formation in Open-Tank Fires
}

\author{
KAZUTOSHI HASEGAWA \\ Fire Research Institute \\ Fire Defence Agency \\ 14-1, 3-chome Nakahara \\ Mitaka, Tokyo 181, Japan
}

ABSTRACT

Hot zones form as an effect of the boiling range of oils, for especially heavier oils. Scattered vapor bubbles are produced throughout most parts of a hot zone. The generation, ascent and growth of these bubbles cause contimal and vigorous convection. The temperature, density and chemical composition of oil in a hot zone are uniform throughout the entire hot zone, both vertically and horizontally. In a tank which is less than $800 \mathrm{~mm}$ in diameter, formation of a hot zone depends laxgely on both material and diameter of the tank. Hot zone formation in a $900 \mathrm{~mm}$ or larger diameter tank depends only on retention of the prescribed quantity of residual fractions of distillation at the surface temperature of the burning oil as determined by a distillation curve. Rate of conversion to a hot zone has a close relationship to the complicated oscillations accompanying the transfer of heat and mass through the interface.

\section{IINTRODUCTION}

Systematic studies on the mechanisms in the occurrence of "boilover" in oil tank fires were conducted principally by Ha.1 ${ }^{1}$ in 1925 , by Burgoyne and Katan ${ }^{2}$ in 1947 and by BIinov and Khudyakov ${ }^{3}$ in 1961 . Other studies associated with the practical problems in boilover, which make firefighting difficult and hazardous, have also been conducted ${ }^{4}, 5$.

Hall was the first to deseribe what has come to be known as the hot zone, a heat wave in the form of a descending heated zone located below the burning surface during the combustion of crude oil in open tanks, as a signal that boilover was about to occur. A thin layer on the surface undergoes a process of distillation. Eventually the heavy ends of this layer sink down to lower levels through succeedingly hot layer, carrying considerable quantities of heat. When they reach the top of the layer of cold oil, a certain amount of ebullition is generated by heat, vaporizing some of the lighter fractions in the cold oil, and makes vapor to rise to the surface. This causes the depth of the hot layer to continually increase. Hall proposed that three conditions had to exist in a tank of burning oil in order for boilover to occur: water had to be present in the oil, heat had to be carried down into the oil well in advance of the burning surface and the oll had to be viscous in nature. 
TABLE I. Dimensions and materials of tanks

\begin{tabular}{|c|c|c|c|c|}
\hline \multirow{2}{*}{ No. } & \multicolumn{3}{|c|}{ Dimensions $(\mathrm{mm})$} & \multirow{2}{*}{ Material of wall } \\
\hline & Inner diameter & Depth & Thickness of wall & \\
\hline 1 & 1000 & 400 & 1.5 & \multirow{5}{*}{$\underset{n}{\text { Steel }}$} \\
\hline $2^{*}$ & 570 & $380 \sim 500$ & 2.0 & \\
\hline 3 & 300 & 100 & 3.0 & \\
\hline 4 & 130 & 100 & 3.2 & \\
\hline 5 & 68 & 100 & 4.0 & \\
\hline 6 & 1250 & 520 & 2.0 & \multirow{4}{*}{ Stainless-steel } \\
\hline 7 & 500 & 294 & 1.5 & \\
\hline 8 & 250 & 120 & 2.0 & \\
\hline 9 & 98 & 100 & 1.5 & \\
\hline 10 & 232 & 120 & 2.0 & \multirow{3}{*}{$\begin{array}{l}\text { Glass (Hario) } \\
n\end{array}$} \\
\hline 21 & 130 & 200 & 2.0 & \\
\hline 12 & 65 & 90 & 1.0 & \\
\hline 13 & 230 & 120 & $2.0+1.0$ & \multirow{3}{*}{$\begin{array}{l}\text { Glass coated on inside } \\
\text { "with asbestos sheet } \\
\text { " }\end{array}$} \\
\hline 14 & 128 & 200 & $2.0+1.0$ & \\
\hline 15 & 63 & 90 & $1.0+1.0$ & \\
\hline
\end{tabular}

*Three identical tanks with the same diameter, used for testing the occurrence of boilover, for temperature and density measurements and for photographing the 500,390 and $380 \mathrm{~mm}$ depths of the respective tanks.

The view of Burgoyne et al. did not differ from that of Hall except in one particular. Burgoyne et al. considered that any heavy ends formed at the surface would actually have a lower specific gravity than the hot zone. There would, nevertheless, be a tendency for mixing to occur due to the stirring effect of the vapors released from the interface at the bottom of the hot zone. The composition of the hot zone appeared to be determined by purely themal considerations.

Blinov et al. pointed out the discrepancies between their experimental results and Hall's theory and proposed a substantially different mechanism for the extension of the hot zone.

Thus two main theories have been advanced to explain the mechanism of hot zone formation. This paper describes many tests under a wide range conditions which were conducted to clarify the mechanism of this phenomenon, especially with regard to the behavior of hot zones and the factors which influence their formation.

\section{EXPERTMENTS}

\section{Apparatus and Procedures}

Tanks. In general, the experiments were conducted using open-topped (vertical) cylindrical tanks to burn oil in. Fifteen tanks with the sizes and materials shown in lable l were used.

Temperature measurement. Detailea observations of temperature changes below the surface of the oil were made using submerged chromel- 


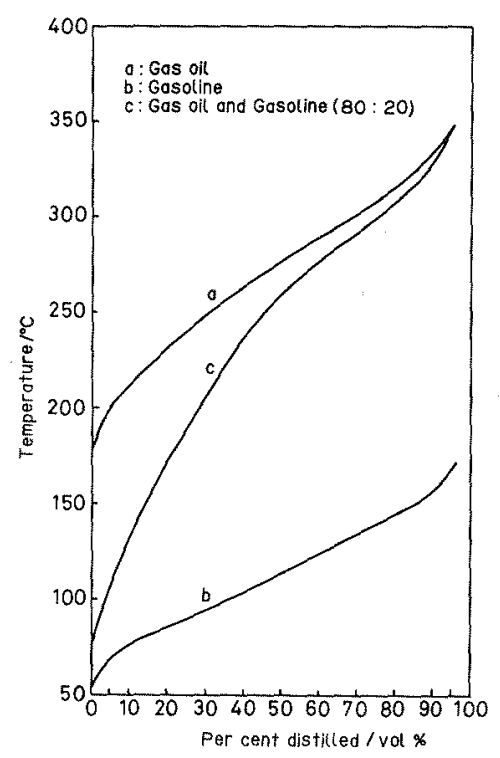

FIGURE 1. Distillation curves
a.Iumel thermocouples located at 5-13 points $5-40 \mathrm{~mm}$ apart vertically near the axis of tanks No.1 - No.9. In some instances, temperatures in a horizontal position were measured by thermocouples at points 10, 100, and $200 \mathrm{~mm}$ from the wall of tank No.2. Two types of thermocouple were used, one with $0.32 \mathrm{~mm}$ diameter bare wires with a time constant of 0.2 sec and the other mounted with a $3.2 \mathrm{~mm}$ diameter sheath, with a time constant of 2.0 sec.

Density measurement. Sample draw-off lines with an inner diameter of $6.0 \mathrm{~mm}$ were connected to tank No.2 at 6 aifferent levels $20 \mathrm{~mm}$ apart vertically, and extending from the tank wall to the center. The density of oil samples was measured using a scale pycnometer.

Photographing. Tank No.2 was equipped with a peephole tube which housea a quartz plate-glass window with an effective diameter of $40 \mathrm{~mm}$.

This tube was aimed from the tank wall toward the center. This peephole was used successfully to make careful and exact observations and records of the behavior of burning oil.

Thermal radiometry. Thermal radiation from the oil fires was measured using a radiometer.

Fuels

Gas oil, gasoline and mixed oil were burnt as fuels. Fig. I shows the aistillation curves of gas oil, gasoline and mixed oil with $80 \%$ and $20 \%$ gasoline. A total of 50 tests were conducted, with the experiments performed in two phases. In the first phase, experiments were developed to observe the influence of the proportions of gas oil and gasoline in the mixed oil on the occurrence of boilover under conditions where water was present at the bottom of the tank. In the second phase, mixed oil with $80 \%$ gas oil and $20 \%$ gasoline, which formed a hot zone easily in tank No.2 and was sufficiently transparent for observation purposes, was burnt repeatediy in order to investigate the conditions which affect the formation of the hot zone. Water was not added and water content was reduced as much as possible through the addition of $8-9$ wt $\%$ of anhydrous sodium sulfate to the mixed oil. The water content was maintained at Iess than 0.01 wt\%.

\section{RESULTS AND DISCUSSIONS}

Occurrence of Boilover

The influence of the proportions of the mixed oils on the 


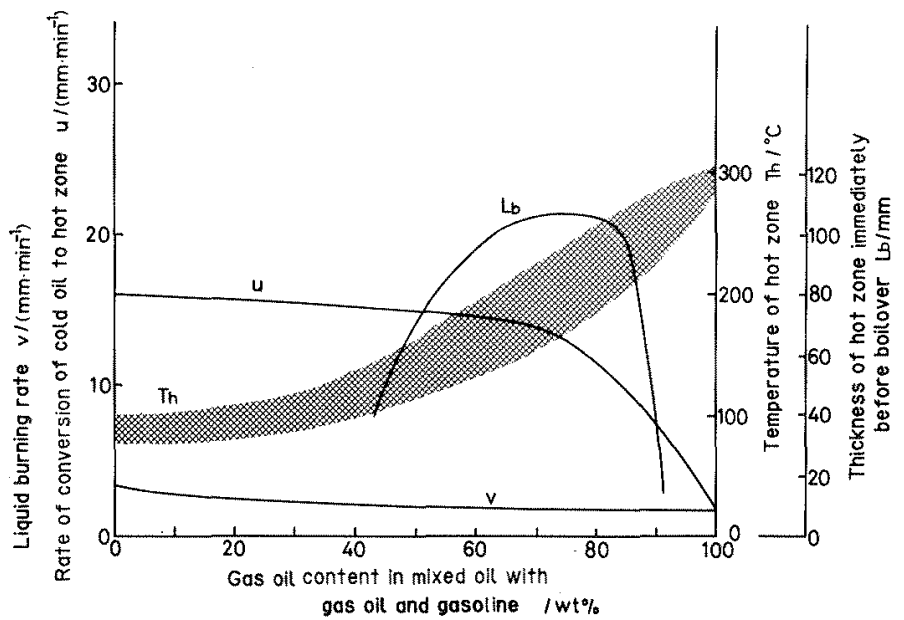

FIGURE 2. Liquid burning rate, rate of conversion of cold oil to hot zone, temperature of hot zone and thickness of hot zone immediately before boilover as functions of the proportion of gas oil in the mixed oil containing gas oil and gasoline. (Tank No.2, initial free-board height: $140 \mathrm{~mm}$; initial depth of fuel: $160 \mathrm{~mm}$; depth of water: $200 \mathrm{~mm}$ )

occurrence of boilover was examined by burning mixed oil in tank No.2 with water at the bottom. The liquid burning rate $\mathrm{v}$, the rate of conversion of cold oil to hot zone $u$, the temperature $T_{h}$ of the hot zone and the thickness of the hot zone immediately before bollover $L_{b}$ were measured as shown in Fig. 2. No hot zone was formed in gas oil alone, but was formed when a small amount of gasoline was added to the gas oil. Boilover occurred in compounds ranging from 50 to $90 \%$ gas oil when the temperature of the hot zone had risen above $130^{\circ} \mathrm{C}$ within the Iimits of $u>v$. Hot zones which caused burning oil in certain circumstances to occur boilover seemed to form due to the effect of the wiath of the boiling range of the oil. The effect of the width tends to be greater in heavier oils. The results indicate the need both for the presence of water which has been superheated most likely by oil with temperatures exceeding. $130^{\circ} \mathrm{C}$, and for the hot zone to achieve a certain thickness in order for violent boilover to occur.

Irradiance from the fire in the most violent boilover of mixed oil with $80 \%$ gas oil and $20 \%$ gasoline was extremely intensified to approximately 50 times the normal irradiance from ordinary fire.

Behavior of Burning 011 During Formation of a Hot Zone

The behavior of burning mixed oil with $80 \%$ gas oil and $20 \%$ gasoline without water was observed in detail during the formation of hot zones using tank No.2.

At or near the surface. Fig. 3-a shows the surface and the hot zone of the burning oil. Bubbles can be seen bursting with the turbulence near the surface. Neither a thin layer, the so-called upper hot zone 


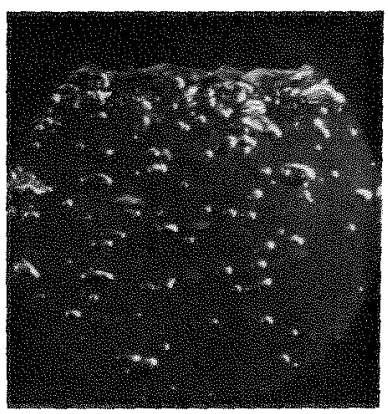

E

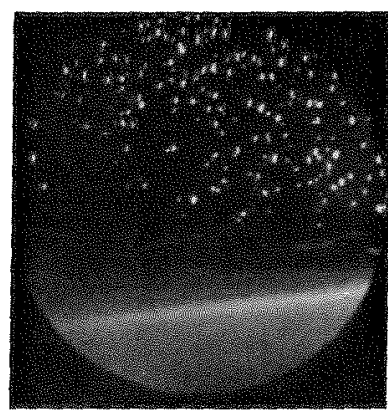

$\mathrm{b}$

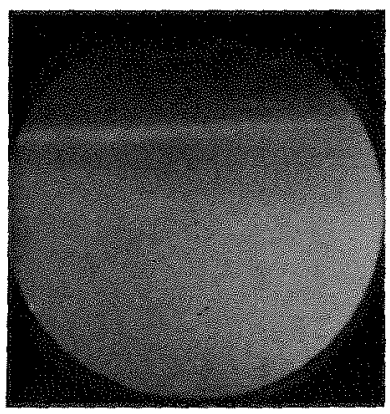

C

FIGURE 3. Behavior of hot zone a. Bubbling at surface; b. Ebullition above interface; c. Aspect near the interface. (Tank No.2, mixed oil. with $80 \%$ gas oil and $20 \%$ gasoline without water)

proposed by Hall ${ }^{1}$ and questioned by Burgoyne et al. ${ }^{2}$, with a much higher temperature than the hot zone, nor a ridge formed by Iiquid weling up at the wall, as reported by Blinov et al. 3 could be verified in these observations, but the hot zone could be clearly in existence. In consequence, it was found that neither the upper hot zone nor the ridge models could be used to explain essentially the formation of the hot zone.

Inside the hot zone. Scattered vapor bubbles were produced in almost a.1 parts of the hot zones observea, within the body or at the bottom. These rose quickly toward the surface, growing gradually larger as they rose, as can be seen in Fig. 3-a and 3-b. This resulted in the nucleation process, which is not explosive but quiet, due to the evaporation of the lightest fractions of oil throughout the hot zone. The natural consequence of the generation, ascent and growth of these bubbles in fact caused both a rising flow and a sinking flow which corresponded to the rising of the bubbles. These flows became the currents of continual and vigorous convection.

Oil samples were taken directly from the tank of burning oil. Oil. densities $\rho_{23}$ and $\rho_{\mathrm{m}}$ were measured at a room temperature of $23.5^{\circ} \mathrm{C}$ and at an oiI. Eemperature of T, respectively. Temperature and density changes related to oil thickness in height 24 minutes after ignition are shown in Fig. 4. The densities as well as the temperatures maintained remarkably constant levels throughout the hot zone when it was about 100 $\mathrm{mm}$ in height. Logically this would mean that the chemical composition of the oil throughout the hot zone would also be constant. Concerning $\rho_{\text {To, }}$ the density of oil in the hot zone at a given temperature was found to be distincty lower than the density of oil in the cold zone at a given temperature. Consequently, the hot zone appeared to be floating stably on top of the cold zone. As for $\rho_{23}$, the density of the oil in the hot zone at a temperature of $23.5^{\circ} \mathrm{C}$ was fund to be higher than that of oil in the cold zone at the same temperature. This obviously means that the heevy fractions of the original oil remain, in the hot zone while the light fractions are continually evaporating off in the distillation process. On the other hand, the temperatures of oil measured at three points spaced apart horizontally at the same depth were nearly constant within a temperature range of $\pm 4^{\circ} \mathrm{C}$ in a temperature measuring range of 


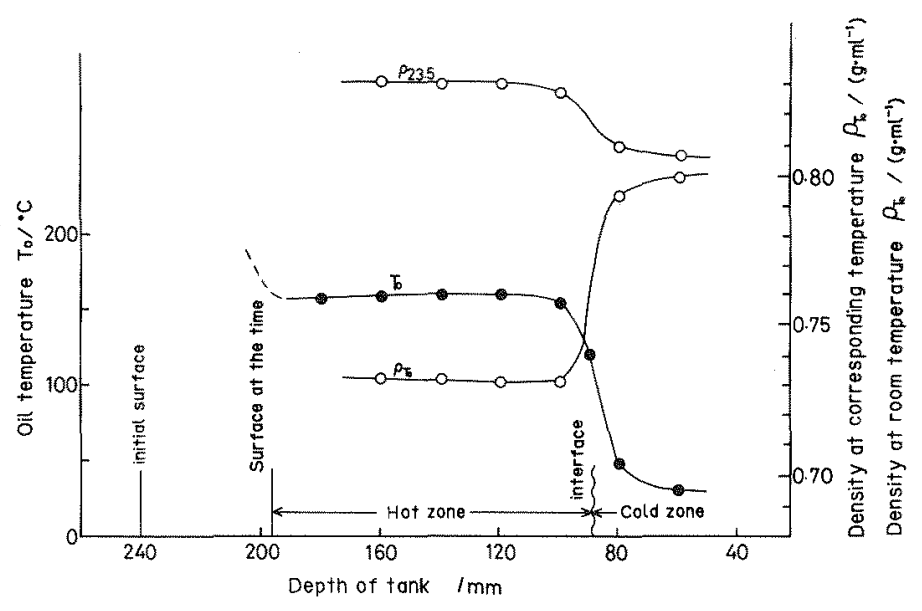

FIGURE 4. Density of oil at corresponding temperature, density at room temperature and oil temperature as functions of tank depth. (Tanis No.2 initial free-board: $150 \mathrm{~mm}$; initial depth of fuel: $240 \mathrm{~mm}$ mixed oil with $80 \%$ gas ojl and $20 \%$ gasoline without water, after burning $24 \mathrm{~min}$ )

$150-300^{\circ} \mathrm{C}$. Since the temperature at a given depth is uniform, then we can naturally conclude that the density and chemical composition at that depth must also be constant.

Therefore, we can reasonably conclude that the vigorous convection makes the temperature, density and chemical composition throughout the hot zone uniform, both vertically and horizontally. This conclusion is in substantial agreement with that of Burgoyne et al. ${ }^{2}$. The temperature and density change with a gentle gradient through the interface, as show in Fig. 4, since the temperatures were measured by a sheath type thermocouple with a larger time constant and because it took approximately 10 sec to extract oil for density measurements.

Near the interface. First of all, it was observed visually through the peephole that the interface between the hot zone and cold zone was a curved surface which sank down while moving up and down. That is, it was observed to vibrate continually. The output of the thermocouples described a cycle in this vibration as the interface shisted alternately and repeatedly across the junctions of the bare wire type thermocouples fixed to the tank, exposing the themocouples alternately to the hot and cold zones. The real interface was clearer than revealed by the monom chrome photographs of Fig. 3-b and 3-c. There was a clearly discernible difference in colors, brown on one side and yellow ocher on the other. The vibrating interface can also be seen in an educational film showing boilovex produced by skum 5 .

The oil over the interface was waving and shimmering with heat, as shown in $F i g .3-b$ and $3-c$. This definitely shows the steady entrainment of fresh oil from the cold zone to the hot zone, due both to the oscillation of the interface and to heat exchange through the interface. The generation of minute bubbles could be seen above the interface. 


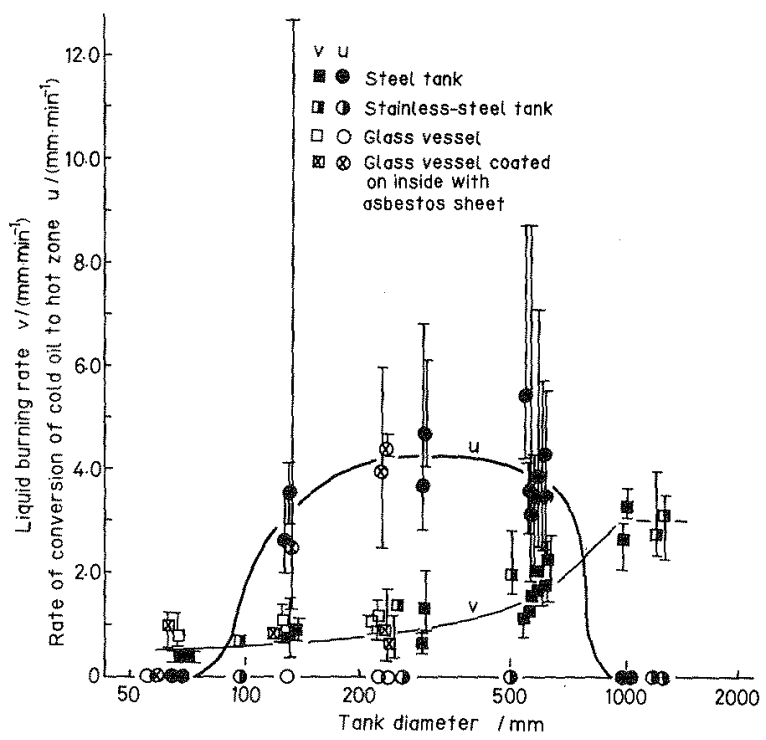

FIGURE 5. Ijiquid burning rate and rate of conversion rate of cold oil to hot zone as functions of the tank diameter. (Mixed oil with $80 \%$ gas oil and $20 \%$ gasoline without water, initial free-board from 10 to $250 \mathrm{~mm}$, approximately proportional to the tank diameter)
Causes of Hot Zone Formation

Investigations

were conducted in

which both the material and the size of tanks used were varied to determine under what conditions hot zones would form. Mixed oil with $80 \%$ gas 0 il and $20 \%$ gasoline, and with as much water removed as possible, was burned.

Fot zone formation dependent on tank size and material. Using the tanks shown in Table I, mixed oil was burnt to determine the influences of the material and the size of the tank on the formation of hot zones, Oil burning rate results are shown in Fig. 5. The burning rate was

hardiy affected by the tank material. However, it varied with the djameter of the tank, following a curve described by the Hottel 6 format for the data of Blinov and Khudyakov ${ }^{3}$. Results on the rate of conversion of cold oil to hot zone, as compared with the burning rate, are shown in Fig. 5. Data for those cases where hot zones did not form are plotted on the horizontal axis as a zero rate. Hot zones did not form in any stainless steel tanks, regardless of the diameter, nor did they form in glass vessels less than $230 \mathrm{~mm}$ in diameter. Hot zones formed in steel tanks with diameters ranging from 100 to $800 \mathrm{~mm}$. The same results were obtained with glass vessels coated on the inside surface with asbestos sheet as with steel tanks when the tank diameters were less than $230 \mathrm{~mm}$. Therefore, in tanks less than $800 \mathrm{rm}$ in diameter, formation of the hot zone depends largely on both the material and diameter of the tanks.

Hot zone formed independent of the presence of water, which is indispensable for the occurrence of boilover.

Surface temperatures of burning oil. Fig. 6 shows the temperatures messured within $3 \mathrm{~mm}$ of the surface of burning oil where bubbles are constantly bursting whether a hot zone has been formed or not. There were notable differences in surface temperatures in tanks with diameters ranging from 200 to $800 \mathrm{~mm}$, depending on the tank material.

Tank diameter less than $300 \mathrm{~mm}$. A thin brownish colored layer about $5 \mathrm{~m}$ thick was observed visually in glass vessels No.10, No.II and No.12. This layer seemed to resemble a hot zone formed on the surface, but it 


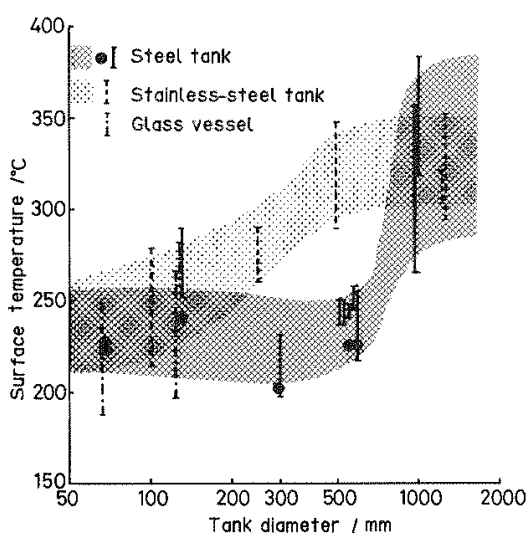

FIGURE 6. Temperature of liquid surface vs. tank diameter. (Mixed oil with $80 \%$ gas $0 i l$ and $20 \%$ gasoline without water, initial free-board from 10 to $250 \mathrm{~mm}$, approximately proportional to the tank diameter) ajd not grow as time passed. This brown layer sank slowly down along the wall only, then accumulated slowly on the bottom of the vessel. This same behavior was observed in stainless steel tanks No.8 and No.9, in steel tank No.5 and in the glass vessel coated on the inside surface With asbestos sheet, No.15. Sinking of this brown layer along the wall was not observed in steel tanks No.3 and No.4, or in glass vessels No.13 and No.14, coated with asbestos sheet, vessels in which hot zones formed.

It is logical to think that the brown layer of liquid consisted of the heavy fractions of oil which should be forming a hot zone. As the brown liquid cooled at the point of contact between the oil surface and the tank wall, its density became higher than that of the original oil, as can be seen in Fig. 4. Thus it was natural for it to sink down along the wall of the

tank. In the cases of tanks No. 3 and No.4, the brown liquid was not cooled by the wall because the steel. wall had a higher thermal conductivity than the walls of stainless steel and glass tanks, thus allowing them to be heated to temperatures higher than that of the surface of the burning oil. In the cases of tanks No.13 and No.14, the asbestos sheet insulated the brown liquid from the cooling effect of the glass wall. We can conclude from these observations that both the material and the diameter of the tank have a great influence on the formation of the hot zone when comparatively small tanks, with diameters of less than $300 \mathrm{~mm}$, are used. These findings may suggest a mechanism whereby thermal conduction through the tank wall, from the rim to the contact surface, and heat-exchange between the wall and the brown layer, could be intricately contributing to the formation of the hot zone.

Tank diameter greater than $300 \mathrm{~mm}$. Fig. 5 and Fig. 6 show that the surface temperatures of steel tanks with diametexs ranging from 300 to $800 \mathrm{~mm}$ in which hot zones formed were notably lower than those of stainless steel tanks. In tanks with diameters exceeding $900 \mathrm{~mm}$, the hot zone would no longer form, whether in stainless steel or steel tanks, and surface temperatures were equally and comparatively high.

It will be noted from looking at the distillation curve of this oil in Fig. I that 30 to $50 \%$ has been distilled off as the oil reaches temperatures ranging from 200 to $250^{\circ} \mathrm{C}$. This temperature range corresponds to the surface temperature of the hot zone in a steel tank of diameter ranging from 300 to $800 \mathrm{~mm}$. However, when the oil has reached temperatures exceeding $300^{\circ} \mathrm{C}$, more than $75 \%$ of the oil, that which contains a somewhat large portion of the heavy fractions, has been distilled off. Consequently, it is logical to consider that a hot zone will be formed by oil which contains a large portion of the heavy fractions in the original oil when the surface temperature is lower, but 
a hot zone will not form at higher surface temperatures due to few heavy residues. In tanks with diameters ranging from 300 to $800 \mathrm{~mm}$, formation of a hot zone depends both on the surface temperature due to the thermal effect of the tank wall and on the characteristics described by the distillation curve.

When the tank has a diameter greater than $900 \mathrm{~mm}$, the burning rate remains constant at the maximum value, as shown in Fig. 5, and combustion is barely affected by the container wall ${ }^{6}$. Consequently the surface temperature is also maintained at a high constant level. The surface temperature of the mixed oil used in these experiments was so high that a hot zone was not formed. It could be universally concluded that the formation of a hot zone depends only on the oil retaining the prescribed quantity of residual fractions of distiliation at the surface temperature of the burning oil as determined from the distillation curve. It could be estimated that the limit for hot zone formation is the retention of $60 \%$ or less of the distillation fractions.

Oscillation of the Intexface and the Conversion Rate of Cold Oil to Hot Zone

The hot zone could not be observed without encountering the oscillating interface between the hot and cold zones. In the experiments performed to obtain the data in Fig. 2, the periodic times underwent changes in a range of 1.8 to 6.0 seconds, dependent on the fuel ratio and the elapsed time. The amplitude of vertical motion was $30 \mathrm{~mm}$ or less. In cases where mixed oil with $20 \%$ gas oil and $80 \%$ gasoline was used in vessels No.13 and No.14, the motion of the interface became extremely intense some time after ignition, after the hot zone had grown a certain extent in size. The interface was still at first, then began moring slowly up and down. The motion continued to increase gradually, with self-excited vibration of the circular interface maintaining its basic form, until the maximum amplitude, about $40 \mathrm{~mm}$, was reached. The interface then disappeared, becoming cloudy, and its motion ceased. After a while, the interface was again created and began its oscillations. This cycle of motions was repeated intermittently, and as a result, the rate of conversion of cold oil to hot zone increased dramatically from 1.3 to $12.7 \mathrm{~mm} / \mathrm{min}$, as shown in Fig. 5. The amplitude and cycle of oscillations seemed to be dependent on the differential density between the hot zone and the cold zone, on the size and material of the tank, etc.

The findings show that there is a close relationship between the rate of conversion of cold oil to hot zone and the complicated oscillations accompanying the heat and mass transfer through the interface. The concept of the oscillation of the interface must be included when formulating the rate of conversion theoretically. From this point of view, the results obtained by Blinov et al? , which state that the thermal diffusivity for the hot zone in benzine is higher than that of copper, may be incorrect. The model of the hot zone proposed by Mil'kov et al. ${ }^{3}$, which gave no consideration to this point, could not express the real phenomena correctly.

\section{CONCLUSIONS}

This paper has presented an experimental study of the mechanism of hot zone formation which leads to boilover in open tank fires. The 
principle conclusions are as follows.

1. Formation of the hot zone seems to be an effect of the width of the boiling range of oils. This seems to be more marked for heavier oils.

2. Scattered vapor bubbles are produced throughout most of the hot zone. The generation, ascent and growth of bubbles cause a continuous and vigorous convection. The temperature, density and chemical composition of oil are uniform throughout the entire hot zone, both vertically and horizontally. The hot zone consists of the heavy residues due to the evaporation of lighter fractions. The hot zone floats stably on the top of the cold zone, as the density of the oil in the hot zone is distinctly lower than that of the oil in the cold zone.

3. In tanks with a diameter of less than $800 \mathrm{~mm}$, formation of a hot zone depends largely on both the material and the diameter of the tank as the result of various types of thermal interactions between the tank wall, the burning oil and the fire.

4. In tanks with a diameter greater than $900 \mathrm{~mm}$, hot zone formation depends only on the retention of the prescribed quantity of residual fractions of distillation at the surface temperature of the burning oil as determined from the distillation curve.

5. The interface sinks as it moves up and down. The rate of conversion of cold oil to hot zone is closely related to the complicated oscillations accompanying the heat and mass transfer through the interface.

\section{ACKNOWLEDGMENTS}

The author thanks Mr. Hirom Kagurasho for his helpful assistance.

\section{REFERENCES}

1. Hall, H. H., "Oil-Tank-Fire Boilovers", Mech. Eng., 47 (7), 540-544, 1925.

2. Burgoyne, J. H. and Katan, L. L., "Fires in open Tanks of Petroleum Products: Some Fundamental Aspects", J. of the Institute of Petroleum, 33, 158-191, 1947.

3. Blinov, V. I. and Khudyakov, G. N., Diffusion Burning of Liquids, T-1490 ASTIA AD 296762, 118-163, 1961.

4. Risinger, J. L., Fire Protection Manual for Hydrocarbon Processing Plants, 2nd ed. Edited by Vervalin, C. H., Gulf Pub. Co. 95-101, $367-373,1973$.

5. SKuM, Svenska Skumslacknings Aktiebolaget, "Oil Tank Fire Extinguishing", Sweden, Mar., 1969.

6. Hottel, H. C., "Certain Laws Governing Diffusive Burning of Liquids", Fire Res. Abstr. Rev., 1, (2), 41-44, 1959.

7. Mil'kov, S. N., Sukhov, G. S. and Yarin, L. P., "Theory of Combustion of Liquids with a Free Surface. II . Quasistationary Regime of Liquid Combustion-Combustion of a Finite "Thickness Layer", Fiz. Goreniya Vzryva, 21 (2), 45-52, 1985. 